\title{
EDITORIAL
}

\section{Aerosol properties and lung deposition}

\author{
G.A. Ferron
}

An important application of an aerosol is to deliver drugs to the lung. Inhaled aerosol particles with a diameter smaller than $5 \mu \mathrm{m}$ can reach virtually all alveoli of the lung, where deposited drugs can act directly on the lung tissue, be absorbed into the blood circulation, or both. This route of delivery has distinct advantages over administration of drugs by ingestion or injection

Understanding particle deposition in the lung is a complex issue, since it depends on the particle size distribution and the respiratory conditions. Therapeutic aerosols are even more complex, since they are hygroscopic and rapidly change their particle size in the lung, and are delivered at high mass concentrations. Even more complicated is the situation in the diseased lung, since the lung anatomy, the airflow profile, and the ventilation distribution may be altered.

Important questions pertaining to therapeutic aerosols are: What is the dose to the lung? and How can the delivery be altered to improve this dose? To answer these questions theoretically, the underlying physical and biological factors affecting therapeutic aerosol delivery and deposition have to be known, in order to develop generally applicable dose-estimation models.

\section{Studies on particle deposition in the normal lung}

A recent historical overview of inhalation therapy by YERNAULT [1] stated that significant improvements in inhalation therapy started during the last century. Since then, new experimental and theoretical techniques have been developed in order to learn more about particle deposition in the lung. In the middle of this century, the development of monodisperse aerosol generators, which produce well-defined, uniformly-sized aerosol particles, stimulated a great deal of research over the last 30 yrs. Numerous investigators have conducted experiments on particle deposition in the whole lung as well as the regional deposition in the extrathoracic airways, the bronchial and the alveolar regions. Deposition in the bronchial and alveolar regions has conventionally been quantified by the respective fractions of the total deposited particles in the thorax that cleared relatively rapidly (within $24-48 \mathrm{hrs}$ ) and relatively slowly (longer than $48 \mathrm{hrs}$ ). A summary of the most

Correspondence: G.A. Ferron, GSF Research Centre for Environment and Health, Project Inhalation, P.O. Box 1129, D85785, Oerschleissheim, Germany. important experiments on total and regional lung deposition for healthy subjects has recently been published by the International Commission on Radiation Protection (ICRP) [2]. The mean values of experimental deposition data are approximated by mathematical expressions, which are then implemented into a computer program [3] that is commercially available on diskette. Since this model is applicable to a wide population of healthy subjects, it is valuable for risk-assessment studies and may also benefit therapeutic aerosol lung deposition studies.

A physical basis for the deposition of aerosol particles in the human lung became available when FINDEISEN [4] published the first lung deposition model. This model uses a lung structure comprised of different lung generations, equations for deposition by sedimentation, diffusion, impaction and interception, and a mathematical model that combines these elements to calculate particle deposition as a function of lung generation. Since Findeisen's initial work, a large number of deposition models have been developed which are based essentially on the same principal. Like FINDEISEN's model, [4], the modern models use a lung structure such as Weibel's dichotomous symmetrical model "A" [5], or, an even more complicated lung structure. In addition, there are newly derived or improved deposition equations for particle sedimentation, diffusion and impaction, empirical equations for extrathoracic deposition, and theoretical equations to calculate the mean deposition in each lung generation. A recent model [6] closely approximates the mean experimental total and regional lung deposition data as collected by the ICRP [2]. Another model has incorporated the growth of hygroscopic particles [7].

Important parameters for lung deposition are: the particle distribution; the respiratory manoeuvre, such as inhalation and exhalation flow rates, tidal volume, pause between inhalation and exhalation; and the shape of the upper airways. The structure of the bronchial and alveolar regions in normal lungs is considered to be of minor influence. However, this is probably not the case for diseased lungs.

\section{Hygroscopic aerosols and lung deposition}

Dautrebande and WaLKEnhorst [8] were first to demonstrate that dry $\mathrm{NaCl}$ aerosol particles grow hygroscopically by as much as six fold during respiration. Later experimental and theoretical studies on hygroscopic aerosol particles revealed that the extent of growth depends 
on a number of important parameters that have been reviewed by MORROw [9] and HILLER [10]. Recent experimental work $[11,12]$ using monodisperse $\mathrm{NaCl}$ particles confirms several aspects of the existing theories on hygroscopic particle growth in the lung.

In addition to the parameters mentioned above, important factors for hygroscopic particle growth and deposition are: the tonicity of the particle materials; the water content of the particles; and the temperature and humidity distribution along the airway walls during inhalation.

In the humid environment of the lung, inhaled hygroscopic particles will gain or lose water until they become isotonic with the fluid lining the airways (physiological saline solution of $0.9 \% \mathrm{NaCl}$ ). Deposition of hygroscopic therapeutic aerosols has been experimentally measured using a gamma camera by WOLFSDORF et al [13]. They demonstrated different deposition distributions in two dimensions over the lung for different aerosol particle sizes. More sensitive deposition studies in three dimensions were performed using single photon emission computer tomography (SPECT) by PHIPPS et al [14]. In the study published in this issue of the Journal, PHIPPS and co-workers [15] found increased central deposition of hypertonic aerosols $(5 \% \mathrm{NaCl}$ in the nebulizer solution) compared to hypotonic aerosols $(0.3 \% \mathrm{NaCl})$ in healthy subjects. This is an interesting finding, which agrees with theoretical estimations of hygroscopic particle deposition in the lungs. In asthmatics, no systematic trend was found in the central deposition between isotonic and hypertonic aerosols; thus, the "state of the airway" may play an additional role.

Theoretical predictions of the deposition of hygroscopic therapeutic aerosols in the lung can now be made, based on the size distribution of aerosols produced by nebulizers and an estimate of the change in aerosol droplet size during transport after nebulization $[16,17]$. For any material, either hygroscopic or nonhygroscopic, this method calculates the total deposition and deposition in each lung generation, as well as the associated surface deposition. By combining the theoretical predictions with the mass of the drug available for inhalation, which can be measured with an on-line aerosol detection instrument, the actual drug dose to each lung generation can be calculated [18].

In this issue of the Journal, the influence of high particle mass concentration on lung deposition of hygroscopic materials has been demonstrated by $\mathrm{CHAN}$ et al [19]. Using SPECT, in normal subjects they found a significant change in the central deposition of hyperdense saline aerosols $\left(\sim 30 \mu \mathrm{g} \cdot \mathrm{cm}^{-3}\right.$ particle mass concentration supplied by the nebulizer liquid) compared to hypodense aerosols $\left(\sim 0.05 \mu \mathrm{g} \cdot \mathrm{cm}^{-3}\right)$ of the same size. The hyperdense aerosol particle mass concentration is typical for most therapeutic aerosols.

\section{Interaction of aerosols with the upper airways}

The main functions of the airways are to distribute air to and from the alveoli and to adjust the inhaled air to the core temperature and humidity. Normally, the tem- perature increases from about 23 to $37^{\circ} \mathrm{C}$ and the humidity from about 8 to $44 \mu \mathrm{g} \cdot \mathrm{cm}^{-3}$. As inspiratory airflow rate increases, there is a large decrease in the air temperature of the upper airways [20].

The hyperdense aerosols used by PHIPPS and co-workers [15] had a solution output rate of $0.23 \mathrm{~g} \cdot \mathrm{min}^{-1}$ at an airflow rate of $8 \mathrm{l} \cdot \mathrm{min}^{-1}$ which corresponds to a droplet concentration of $29 \mu \mathrm{g} \cdot \mathrm{cm}^{-3}$ without taking evaporation into account. In the case of inhaled hyperdense droplets with a high $\mathrm{NaCl}$ concentration of $5 \%$, the airways have to add $160 \mu \mathrm{g} \cdot \mathrm{cm}^{-3}$ of water to the droplets to attain equilibrium between the droplets and the airways. This amount of water is much higher than the amount of water the airways have to provide to humidify inhaled air when breathing at rest. It is more comparable to the humidification load the lung must supply when the minute ventilation is increased fourfold, such as during heavy work. However, these two humidification loads are not identical. With increased airflow, the humidification of air occurs only in the upper airways, whereas with the highly dense, high salt-concentration aerosol the humidification occurs throughout the airways system. More distal parts of the lung are involved with the latter humidification because it takes longer than $10 \mathrm{~s}$ for the $3.8 \mu \mathrm{m}$ droplets used in this study to grow to a size of $8.5 \mu \mathrm{m}$ and reach equilibrium [21].

Interpretation of the results by CHAN et al. [19] is less simple. They found a larger difference between the regional deposition of hypodense aerosols that were isotonic and hypertonic as compared to the same measurements with hypertonic hyperdense aerosols [15]. Based on our current understandings of hygroscopic aerosol behaviour in the upper airways, a smaller or even no effect would be expected. Thus, an additional unknown factor must be responsible for this result.

\section{Modelling in aerosol therapy}

Important factors for the use of nebulizers in therapy are: the aerosol particle size distribution; the mass concentration of water and solute from the nebulizer; the change in size of the aerosol particles and their loss during transport; and the respiratory conditions.

Unfortunately, no instrument currently exists that can accurately characterize hygroscopic aerosols. Therefore, the choice of monitoring system is a compromise. On-line detectors such as Fraunhofer light-scattering detectors [22], and phase-Doppler detectors [18], have problems monitoring particle sizes below $1 \mu \mathrm{m}$. Additionally, the solute concentration and density in the aerosol droplet have to be estimated. Impactor measurements of the wet aerosol [15, 19], and of the dried aerosol [23], give information in seven size range intervals. Thus, information in real time is hardly possible. An intercomparison of detector systems is needed.

After aerosol production, the droplets will partly evaporate to humidify the air. Assuming equilibrium, the mean change in size can be calculated [17]. However, particles larger than about $3 \mu \mathrm{m}$ will not reach 
equilibrium [21]; thus, these particles hardly change their size, whereas smaller particles reach equilibrium with the air. Additionally, the change in temperature plays an important role.

Models on aerosol particle deposition calculate the mean deposition in each lung generation using an idealized equation for stable laminar airflows. However, the airflows at bifurcations are very complicated [24], and far from being stable and laminar. Since the geometry and ventilation changes in the diseased lung probably affects flow profiles, flow profile analysis is one approach to model the deposition in the diseased lung. This information can be used to model the deposition of therapeutic aerosols.

\section{Perspectives}

To develop better theories of lung deposition of aerosol particles, a sensitive lung imaging system and well-characterized experiments are needed. The two experimental studies presently $[15,19]$ published in this issue of the Journal have characterized their subjects lung function and the size distribution of the aerosol particles well. The data of PHIPPS and co-workers [15] agree with current theory whereas the data of CHAN et al [19] do not. Further experimental studies are needed to confirm and explain this finding. If it is found to be true, the theory will have to be modified to account for the interaction of aerosol particles with the upper airways. However, for diseased lungs there is insufficient information available on the heat and water vapour transport, the lung structure and the respiratory conditions. Hence, it is not yet possible to make reliable estimations of aerosol particle deposition for lung disease.

Acknowledgments: The author thanks J.D. Blanchard and M. Schulz for their comments and discussions.

\section{References}

1. Yernault JC. Inhalation therapy: A historical perspective. Eur Respir Rev 1994; 4: 65-67.

2. International Commission on Radiation Protection (ICRP). Human respiratory tract model for radiological protection. Publication 66. Ann ICRP 1994; 24(1/4): (in press).

3. Jarvis NS, Birchall A, James AC, Bailey MR, Dorrian MD. LUDEP 1.0 - Personal computer program for calculating internal doses using the new ICRP respiratory tract model. NRPB-SR264. 1993; National Radiological Protection Board, Chilton, UK.

4. Findeisen W. Über das Absetzen kleiner in der Luft suspendierter Teilchen in der menschlichen Lunge bei der Atmung. Pfügers Arch 1935; 236: 367-379.

5. Weibel ER. In: Morphometry of the Human Lung. Berlin, Springer Verlag, 1963.

6. James AC, Stahlhofen W, Rudolf G, et al. The respi- ratory tract deposition model proposed by the ICRP Task group. Rad Prot Dos 1991; 38; 159-165.

7. Ferron GA, Kreyling WG, Haider B. Inhalation of salt aerosol particles. II. Growth and deposition in the human respiratory tract. J Aerosol Sci 1988; 19: 611-631.

8. Dautrebande L, Walkenhorst W, Über die Retention von Kochsalzteilchen in den Atemwegen. In: Inhaled Particles and Vapours. Oxford, Pergamon Press. 1961; pp. 110 119.

9. Morrow PE. Factors determining hygroscopic aerosol deposition in airways. Physiol Rev 1986; 66; 330-376.

10. Hiller FC. Health implications of hygroscopic particle growth in the human respiratory tract. J Aerosol Med 1991; 4: 1-23.

11. Gebhart J, Anselm A, Ferron G, Heyder J, Stahlhofen W. Experimental data on total deposition of hygroscopic particles in the human respiratory tract. In: Masuda S, Takahashi K, eds. Aerosols, Science, Industry, Health and Environment. Oxford, Pergamon Press. 1990, pp. 1299-1302.

12. Anselm A, Heibel T, Gebhart J, Ferron G. "In vivo" studies of growth factors of sodium chloride particles in the human respiratory tract. J Aerosol Sci 1991: 22: S427-430.

13. Wolfsdorf J, Swift DL, Avery ME. Mist therapy reconsidered: An evaluation of the respiratory deposition of labelled water aerosols produced by jet and ultrasonic nebulizers. Pediatrics 1969; 43: 799-808.

14. Phipps PR, Gonda I, Bailey D, Borham P, Bautovich G, Anderson SD. Comparison of planar and tomographic gamma scintigraphy to measure the penetration index of inhaled aerosols. Am Rev Respir Dis 1989; 139: 1516-1523.

15. Phipps PR, Gonda I, Anderson SD, Bailey D, Bautovich G. Regional deposition of saline aerosols of different tonicities in normal and asthmatic subjects. Eur Respir $J$ 1994; 7: 1474-1482.

16. Ferron GA, Karg E, Peter J. Estimation of deposition of polydisperse hygroscopic aerosols in the human respiratory tract. J Aerosol Sci 1993; 24: 655-670.

17. Ferron GA. The scientific basis for aerosol therapy using nebulizers. Eur Respir Rev 1994; 4: 95-98.

18. Stapleton $\mathrm{KW}$, Finlay WH, Zuberbuhler P. An in vitro method for determining regional dosages delivered by jet nebulizers. J Aerosol Med 1994; (in press).

19. Chan HK, Phipps PR, Gonda I, et al. Regional deposition of nebulized hypodense nonisotonic solutions in the human respiratory tract. Eur Respir J 1994; 7: 1484-1489.

20. McFadden ER Jr, Pichurko BM, Bowman HF, et al. Thermal mapping of the airways in humans. J Appl Physiol 1985; 58: 564-570.

21. Ferron GA, Soderholm SC. Estimation of the times for evaporation of pure water droplets and for stabilization of salt solution particles. J Aerosol Sci 1990; 21: 415-429.

22. Merkus M, Marijnissen J, Jansma E, Scarlett B. Droplet size distribution measurements for medical nebulizers by the forward light scattering technique (laser diffusion). J Aerosol Sci 1994; 25 (Suppl): (in press).

23. Roth C, Gebhart J. Inertial classification of droplets produced by medical nebulizers. J Aerosol Sci 1994; 25(Suppl): (in press).

24. Jan DL, Sharpiro AH, Kamm R. Some features of oscillatory flow in model bifurcation. J Appl Physiol 1989; 67: 147-159. 